INTERNATIONAL UNION OF PURE

AND APPLIED CHEMISTRY

APPLIED CHEMISTRY DIVISION

COMMISSION ON PESTICIDE RESIDUE ANALYSIS

IUPAC Reports on Pesticides (8)

\title{
STATUS REPORT ON CLEAN-UP AND DETERMINATION PROCEDURES
}

\author{
Prepared for publication by \\ I. S. TAYLOR \\ Regional Laboratory (Victoria), \\ Melbourne, Australia \\ H.-P. THIER \\ University of Münster, FRG
}

PERGAMON PRESS

OXFORD • NEW YORK - PARIS - FRANKFURT 
STATUS REPORT ON CLEAN-UP AND DETERMINATION PROCEDURES

I.S. Taylor

Regional Laboratory (Victoria), Australian Government Analytical Laboratories, POB 2809AA, Melbourne, Vic. 3001, Australia

H. -P. Thier

Institute of Food Chemistry, University of Minster, Piusallee 7, D-4400

Munster, Federal Republic of Germany

\begin{abstract}
Evaluations of some extraction procedures for determining pesticides in plant material, soils and fat have been made. Polymeric adsorbents have been used for extracting pesticides from water. Further investigations are described into column adsorption chromatography, gel permcation chromatography and h.p.1.c. Trends in residues analysis generally are discussed. Recent progress in design and methodology of detectors, derivativization, columns and computer processing in g.1.c. and advances in h.p.l.c. are reviewed.
\end{abstract}

\title{
I. CLEAN-UP PROCEDURES
}

A multitude of methods for the extraction and clean-up of samples, which are composed, however, of only a few fundamental operational steps in slight modifications, are now avallable. In recent years no basically new clean-up techniques have emerged but some advance has been made upon the methodology previously adopted. Interest has been focused mainly on the multiple residue procedures in order to simplify their mode of operation, to extend their applicability to a broader range of pesticide-substrate combinations, to check their reproducibility and to introduce automated clean-up steps for routine control.

In the gas chromatographic analysis of the organophosphate and organonitrogen compounds the clean-up of extracts does lose its importance owing to the widespread and more specific gasliquid chromatography (GLC) with the element sensitive phosphorus and nitrogen detectors. Thus, a suitable extraction procedure combined with a partitioning step is often sufficient for plant material or water.

Concerning organochlorine pesticides particular emphasis has been given to the residues in fats and fat-containing foodstuffs, most of them coming from animal origin. A rather vigorous separation from co-extractives is still required here before GLC with the relatively unspecific electron capture detector.

\section{EXTRACTION}

Several recent publications deal with renewed evaluations of the effectiveness of solvents for the extraction of samples. For instance, Aoki et al (Ref 1) compared 5 solvents for organophosphates in plant material, Smith (Ref 2) studied acetonitrile for acidic and neutral herbicides from soils, Mes and Campbell (Ref 3) used different solvent mixtures and homogenisers for organochlorine compounds in adipose tissue, and Swift and Settle (Ref 4) eluted organochlorines from fat distributed on Florisil with acetonitrile containing $10 \%$ water. Such tests were generally made with samples spiked with added pesticides, and the question of extractability of genuine residues was not considered.

Smart et al (Ref 5), however, included samples having incurred residues of organophosphates in a comparison of methods but did not find significant differences.

For the extraction of water the interest was focused on the use of the Amberlite XAD-2 and $\mathrm{XAD}-4$ as well as similar polymeric resins which proved to be suitable for a wide range of residues, namely organochlorines (Ref 6), organophosphates (Ref 7) and phenoxy acid herbicides (Ref 8). Besides these a variety of other adsorbents have been successfully applied. Wu and Suffet (Ref 9) proposed a Teflon mixing coil apparatus for continuous liquid-liquid extraction. Agemian and Chau (Ref 10) showed, however, that a simple extraction with solvent can nevertheless still yield good results. 


\section{PART IT IONING}

In most of the usual methods for plant material a water-miscible solvent e.g, acetone or acetonitrile is preferred for extraction. After dilution with water the residues are generally partitioned into a solvent such as methylene chloride which can be readily evaporated to dryness. Fukuhara et al (Ref 11) studied some solvents for their effectiveness in transferring organophosphate pesticides from aqueous solution. McLean et al (Ref 12) demonstrated that this general step can nevertheless give rise to problems with individual substances.

Polar pesticides, of course, are only poorly recovered from the surplus of water in this way. The trend is therefore moving to the opposite mode of operation, that is, to keep the residues in organic solution and to remove the water coextracted from the crop material. Evaporation of the organic solvent yields good recoveries of even highly polar compounds which can be analyzed directly by GLC with the selective nitrogen and phosphorus detectors, or cleaned up further by an appropriate broad spectrum technique such as gel permeation chromatography or sweep co-distillation. For instance, acetone extracts containing organophosphates were treated with petroleum ether-methylene chloride and with methylene chloride only by Luke et al (Ref 13) and by Wagner and Frehse (Ref 14), whereas Hild and Thier (Ref 15) proceeded in the same way with acetonitrile extracts.

For the purification of fat extracts the partitioning step between hexane and dimethyl formamide or dimethyl sulfoxide is still used when a high purity is required. Recently, Dale and Miles (Ref 16) succeeded in isolating some organophosphate and carbamate insecticides from fatty foodstuffs by means of a partitioning column consisting of acetonitrile on Florisil. Friestad (Ref 17) derived a partitioning step using small volumes of petroleum ether and dimethyl sulfoxide for crop material emphasizing minimal manipulation.

For confirmation of some nitro-groups containing pesticides Lawrence et al (Ref 18) proposed chemical reduction. Partitioning the resulting amino-compounds appears to be an additional way of eliminating interferences. Also partitioning with ion pair formation as described by Akerblom (Ref 19) may be helpful for the isolation of appropriate compounds.

\section{ADSORBENT COLUMN CHROMATOGRAPHY}

In practice, adsorption column clean-up does remain the outstanding feature in the purification of extracts before GLC with electron capture detection. Florisil is still the most widely used adsorbent and it is involved in many clean-up methods for fatty or non-fatty foods hitherto proposed. In the past few years many publications have dealt with comparisons of such methods but generally no gross discrepancies in the results were observed. The Association of Official Analytical Chemists (AOAC) method appeared in many cases to be the most suitable but also the most time-consuming. Recently, McMahon and Burke (Ref 20) listed the analytical behaviour and elution patterns from Florisil for over 300 pesticidal substances in AOAC methodology.

Experience, however, has shown that Florisil is not available in all countries in a sufficientiy constant quality. At the same time some analysts are increasingly aware of the similarly good results obtainable with alumina or silica gel as standardizable and less expensive adsorbents.

Telling et al (Ref 21), for instance, proposed a column of activity-4 alumina for the adsorption of fat, eluting organochlorine residues with hexane. Steinwandter and Schluter (Ref 22) isolated organochlorines from lipids by elution with petroleum ether from silica gel containing as much as $30 \%$ water. In the Netherlands a programmable low pressure 1iquid chromatograph has been constructed (Ref 23) with 5 channels consisting of 2 colums of the "throw-away" type for adsorption chromatography with alumina and silica gel.

A very promising tool for clean-up and fast concentration will perhaps be the use of small disposable cartridges (Ref 24), commercially avallable in the normal (silica gel) and reverse phase mode. In a preliminary communication, Getz (Ref 25) had pointed out the unique separation properties of crystaline macro porous silica gel and predicted universal application in residue analysis but this has clearly not yet found a broader practical application.

Possible adverse effects of adsorbents need to be borne in mind. Thus, Huckins et al (Ref 26) detected polychlorobiphengls (PCB's), sulfuric acid and other interfering contaminants in several batches of silicic acid. Losses of 2,4-D caused by a plug of glass wool were observed by Osadchuls et al (Ref 27), but they were able to use this effect positively for a method in which chlorophenoxy acids are adsorbed onto a column of glass beads and are directly esterified on glass surface. 
In the analysis of fatty foods adsorbent column clean-up can be readily miniaturized, Several recent publications (Refs 28, 29) deal with the use of micro Florisil columns, and a corresponding small-scale procedure published by stifve and Brand (Ref 30 ) has been successfully studied by several laboratories. Current experience shows that specially the micro colum of silica gel containing $30 \%$ water proposed by Steinwandter and Schluter (Ref 31) yields very pure extracts.

Such micro methods appear to be very promising for routine analyses of organochlorines in fatty foods as they offer economy in solvents and materials and reduce health and fire hazards. The sensitivity, however, is of course less than with the corresponding largescale procedures.

\section{GEL PERMEATION CHROMATOGRAPHY (GPC)}

GPC has proved to be a highly valuable tool for the isolation of pesticides. It 1s particularly suitable for the removal of the bulk of lipids in the analysis of fatty foods.

The separation system originally introduced by Stalling and consisting of Bio Beads SX-2 and. cyclohexane did already yield results superior to acetonitrile partitioning and Florisil chromatography and was also successfully used for the clean-up of great quantities of fat when preceded by an adsorption step with Micro Cel-E. The method was meanwhile considerably improved by the use of Blo Beads SX-3 and ethyl acetate-toluene $(3+1)$. Johnson et al (Ref 32) confirmed that a broad range of organochlorine (including PCB) and organophosphate pesticides could be recovered in good yields from fats and o1ls. Except for several chlorophenoxy herbicide esters the extracts required no further clean-up prior to GLC.

A particular advantage of GPC is that it can be readily automated and that appropriate instruments are commerctally avallable. Thus, the Autoprep 1001 fitted with a Bio Beads SX-3 colum allows automatic handing of 23 samples and has already found wide distribution for routine analyses. Several authors have found it to be very suitable for determinations of organochlorines and organophosphates in fats as well as for similar purposes.

GPC with Bio Beads and sometimes other cross-linked polystyrene resins is also frequently used with success for the separation of pesticides (and PCB's) from co-extractives in plant material (Ref 33) or various food commodities (Ref 34). The purity obtained is generally sufficient for GLC with the element-sensitive detectors. For electron capture detection, however, a further clean-up of extracts with alumina or Florisil is often necessary here (Refs 32, 35). The same holds true for GPC with Sephadex LH-20 (Ref 36) wh1ch is of minimal importance in residue analysis. It was used for instance for analyses of organochlorines in cereal crops combined with a sulphuric acid treatment (Ref 37 ).

\section{HIGH PERFORMANCE LIQUID CHROMATOGRAPHY (HPLC)}

Given the increasing importance of HPLC as a determinative step in residue analysis, interest in its application for the clean-up of extracts has been minimal. Nevertheless it might be considered as a useful adjunct for multiresidue screening procedures.

Earlier work had already shown that columns containing micro particulate silica gel (e.g, Corasil II or Porasil A) are very suttable for the separation of organochlorine compounds from 1ipids (Ref 38). In a similar manner Merckosorb SI 60 was successfully used for the final purification of extracts from various types of fatty and non-fatty foods in PCB analysis (Ref 34 ).

Special attention should be given to the applicability of HPLC to separation problems where highly polar compounds are involved. As examples, Ramsteiner and Hbrmann (Ref 39) coupled a HPLC system with a cholinesterase inhibition Auto Analyzer for the determination of polar organophosphates and carbamates, while Still and Mansager (Ref 40) and Mittelstaedt et al (Ref 41) applied the techniques for the isolation of metabolites and for the separation of polar conjugates from thei $r$ parent compounds.

\section{SWEEP CO-DISTILLATION}

Sweep co-distillation is a still expanding and readily automated multiresidue technique which allows the separation of a quantity of pesticide residues from non-volatile coextractives without being affected by the polarity of the compounds. It can be applied to the analysis of plant material, fatty foods, and soll. Earlier work had shown that it is particularly suitable for the clean-up procedures followed by GLC with the phosphorus and nitrogen selective detectors, whereas for electron capture detection an additional clean-up step often remains necessary. 
Rather simple devices, such as a modified Storherr tube integrated to the detector oven of a gas chromatograph (Ref 42) or the 4 column Kontes apparatus (Ref 43), have been successfully used for the analysis of organochlorines and organophosphates in fats, milk or crops. Besides these, highly automated and sophisticated apparatus is commercially available which enables the performance of this technique to be fully utilized for routine analyses. A sulphuric acid/Celite column can be adapted as an optional automatic clean-up step (Ref 44). Experience with a great number of organochlorine and organophosphate insecticides as well as with triazine herbicides and their desalkyl metabolites is still being gained. (Ref 45).

\section{MISCELLANEOUS}

For the substituted urea herbicides, hydrolysis followed by steam distillation and concentration of anilines in a liquid-liquid extractor is still the method of choice adopted by Caverly and Denney (Ref 46).

A simple and low cost technique such as entrainment distillation with water and continuous extraction of the distillate presents itself of course for other volatile residues. An essential oil distilling apparatus, recommended earlier for distillation of organochlorines from plant material, has now been used in an improved version by Oka et al (Ref 47) for analyses of fats. The only drawback seems to be the rather Iong distillation time required for quantitative entrainment. Veith and K1wus (Ref 48) proposed a similar technique for the distillation of organochlorines from water, sediments, and tissues. Another application was demonstrated by Ott and Friestad (Ref 49) who used a modified standard Technicon device for micro-distillations in the analysis of chlorophenols derived from MCPA and 2,4-D.

The separation of residues from large quantities of fats and oils by lipid adsorption on calcium silicate (Micro Cel-E, Calflo E) was considerably improved by Specht (Ref 50). Collaborative study proved this technique to be well suited for a multitude of organochlorine and organophosphate pesticides and for a variety of foodstuffs, even for crucial pesticidesubstrate combinations. Removal of large quantities of lipids from a fat solution in hexane by means of concentrated sulphuric acid has been evaluated by Velerov and Aharonson (Ref 51).

\section{CONCLUDING REMARKS}

Most of the clean-up procedures nowadays available will yield reliable and reproducible results when practised by a trained and competent analyst. The main precondition is of course that his laboratory has gained abundant experience with the methods in question.

When comparing different clean-up procedures in collaborative studies with laboratories well acquainted with the methods tested, it has been observed time and again that, in most cases, the mean results and the repeatability standard deviations tallied well within the same laboratory, no matter which type of clean-up was used. In addition to current experience it can be concluded, therefore, that most of the clean-up steps are largely interchangeable.

In consequence, the relatively high interlaboratory deviations which can be found in collaborative studies should not be attributed only to the methods of clean-up used. It is obvious that sources of error inherent in the laboratories, such as solvent evaporation or gas chromatographic determination, may play a more important and sometimes unexpected role.

While analytical methods for individual pesticides remain doubtless important in some areas, analysts are appreciating more and more the multiresidue procedures. Most of the appropriate methods, however, are of value only for the parent pesticidal compounds and do not cover their significant metabolites. One of the primary targets for future development should be to include at least the metabolites with any toxicological interest. As many of them may differ in polarity from the parent compounds, only a few clean-up possibilites might come into question.

Most of the clean-up methods are devised for a limited group of pesticides, sometimes fortuitously selected, with similar structures and properties. Considering the multitude of possible residues there are, however, for each situation other compounds passing through the clean-up steps which can cause interferences or erroneous results in the final determination. For a recommendable method it should be the case, therefore, that the analytical behaviour of at least the most common other pesticides, for which the procedure is not intended, be investigated beforehand. The AOAC methods, for instance, were tested in this way by McMahon and Burke (Ref 20).

Another point to be considered is the large gap in information about pesticides introduced in the past few years. As a consequence multiresidue procedures, including the new mainly water soluble and systemic insecticides and fungicides, are lacking today. Perhaps the new partitioning mode mentioned above can form an appropriate starting-point. 
In addition it is, no doubt, due to a lack of information that a number of analyses for regulatory purposes are performed today for pesticides which have been superseded by others not detectable by the clean-up methods in current usage.

It seems that real progress in methodology has essentially ceased since the fundamental developments in the mid-sixties, and for a decade analysts have been merely engaged to modify the basic concepts time and again without taking in consideration the changing significance of the residues analyzed.

As physical and chemical properties of pesticides used in crop protection become more and more diverse the classic clean-up by partitioning and adsorbent column chromatography is felt to lose its hitherto domination role for adequate multiresidue analysis. clean-up can be anyhow reduced for GLC with the element sensitive detectors. The same might be possible, to a certain extent, for electron capture detection if the outstanding separation techniques of GLC with glass capillary columns were used more frequently. With HPLC as a determinative step, however, a rather vigorous clean-up seems to remain a necessity since comparably selective HPLC detectors are not yet available. Also simple methods of analysis, with e.g, thin layer chromatographic determination, do still require effective clean-up steps.

As was outlined above, only few of the clean-up techniques available will meet the future requirements of an up-to-date pesticide residue analysis. The most generally applicable and readily automated, though less vigorous, clean-up steps such as gel permeation chromatography are expected to become the most appropriate tools.

\section{DETERMINATION PROCEDURES}

This part of the report does not include determinative methods using thin-layer chromatography or colorimetry. Emphasis is placed on gas-liquid chromatography, which is treated under the headings of:- detectors; derivatisation; and columns. Also included are liquid chromatography, computer processing and automation.

\section{GAS-LIQUID CHROMATOGRAPHY}

Detectors. Aue (Ref 52) has reviewed the subject comprehensively, and Coch rane and Greenhalgh (Ref 53) have compared and evaluated alkali flame, Coulson and flame photometric detectors.

Electron-capture detectors continue to dominate in organochlorine determinations. Their high sensitivity outweighs their sometimes uncertain operation, particularly in linearity, baseline return, and noise. Lovelock (Ref 54) describes a solute-switching and synchronous demodulation of signal to improve the detector. Jensen et al (Ref 55) have dealt with the problem of sulphur interferences. Sevcik (Ref 56) achieved three-decade linearity and improved detection by using a nitrogen-pentance carrier gas in place of methane-argon. Brechbuhler et al (Ref 57) obtained high sensitivity, and minimised peak-spreading, with a "micro"-electron-capture detector having a geometry permitting very small cell volume.

Electron-capture and flame-ionisation detectors are used simultaneously by Bachmann et al (Ref 58) to improve identification and quantitation; the ratio of responses of the two detectors is characteristic of many compounds, depending upon their electron-afinity versus carbon content and other properties affecting flame ionisation.

Phosphorus and nitrogen detectors, especially the former, are basic to the analysis of a large number of pesticide residues. The above-mentioned on selective detectors by Cochrane and Greenhalgh (Ref 53) is especially of value here. Thermionic or halide-flame detectors have been refined for greater stability, but flame photometric detectors (FPD) are becoming more favoured. Thermionic detectors require more attention and expertise to maintain their advantage in sensitivity. They can be made to perform with an order of magnitude greater sensitivity in experienced hands, but can mislead badly under less expert direction. The trend toward FPD (a more even detector) reflects this. In a collaborative study of organophosphorus residues in stored grain, Desmarchelier et al (Ref 59) reported more than twice as many thermionic as photometric detectors in use (1977). However, in over thirty papers within the subject area, in the period March 1977 to March 1978, the proportion of photometric detectors increased from one-third to two-thirds.

Greenhalgh et al (Ref 60) described optimisation techniques for FPD in both phosphorus and sulphur modes, a timely study to assist a tedious operation. A useful improvement to thermionic detectors has been the introduction of the electrically heated rubidium sulphate bead, marketed by Perkin-Elmer. Kolb et al (Ref 61) described an interchangeable carbon/ nitrogen/phosphorus detector employing the principle. Other observations of thermionic effects were made by Mellor (Ref 62), and Burgett et al (Ref 63), the latter using a low- 
temperature excited plasma in lieu of a conventional flame, together with an alkall saltimpregnated ceramic cylinder electrode. A further step was taken by Greenhalgh et al (Ref 64) who incorporated rubidium hydroxide into quartz, thus avoiding the interference of other elements in glass. Substantial increases in sensitivity for both nitrogen and phosphorus, low noise level, and long 11 fe of the bead are reported. While the electrolytic conductivity detector is more specific than thermionic or photometric detectors for these elements, they appear to retain an advantage in sensitivity at this stage.

Mass spectrometry as a detector for GLC is expensive for routine work, but is unique in its capability for specific identification of chromatographic analytes. Luke and Dahl (Ref 65) identified difficult organophosphate dip residues by gas chromatography/mass spectrometry (GCMS). The increase in its use has included specific-ion monitoring at a single mass number, and the highly specific simultaneous monitoring of a number of selected characteristic fragment ions (Baldwin et al, Ref 66). GCMS is also employed in other ways, such as that by Stan (Ref 67) in collecting total mass spectra and correcting for known or separately determined background.

Derivatisation. Formation of derivatives in residue analysis is a necessity when the analyte is labile or otherwise troublesome. One of the most widely used methods is trifluoroacetylation, such as is employed by Worobey and Webster (Ref 68) for diflubenzuron, and Coburn et al (Ref 69) for carbamates. Success depends greatly upon the substrate in which the residue is sought. A disadvantage of many derivatising agents is their tendency to form chromatographable compounds from substrate just as easily as from residue analyte. Cleanup before or after derivatisation is often necessary, followed in some cases, to obtain greater specificity, by a second derivatisation. The range of recoveries tends to become broad, and unacceptably low. The "problem" compound ethylenethiourea is a good example. It has been measured by many detection systems with varfable success, and using a multitude of derivatisation procedures. Levels of $0.01 \mathrm{Ingk}^{-1}$ have been achieved, but are difficult to reproduce in routine regulatory laboratories. Ripley and Simison (Ref 70) used the S-(3trifluo romethylbenzene) derivative of $\mathrm{King}$ (Ref 71), then, after cleanup, formed the Ntrifluoracetyl-secondary derivative, which was then measured by GLC with FPD sulphur detection. Standard additions were psed for quantitation down to $0.01 \mathrm{mg} \mathrm{kg}^{-1}$, with, however, a statedvariability of $+0.01 \mathrm{mg} \mathrm{kg}$. This level of precision renders the method less than sultable for regulatory work at this low concentration, although admirable for experimental trials. Otto et al (Ref 72), finding derivative methods unsatisfactory, developed a method in which the ethylenethiourea is treated so as to minimize losses, and determined by GLC (FPD) without derivatisation. Perhaps more perseverance in development of analytical methods directly for the original residue compound might in some cases obviate the need for the complications of derivatisation.

Alam (Ref 73) determined hexachlorobenzene, which, while a good GLC analyte itself, can be confused with other electron-capturing species of high vapour pressure, unless cleanup is of a very high order; the HCB was converted to pentachlorophenol, then to the acetate, and measured by microcoulimetric detection (the method was applied to formulations, not residue quantities, but may be of value in confirmatory techniques).

West and Day (Ref 74), in an unusual derivatisation, measured ancymidol as the bromide after treatment with phosphorus tribromide. Bromine derivatives are responsive to electron capture detection, but often lack stability for GLC.

Luckas et al (Ref 75) have determined polychlorinated buphenyls together with organochlorine pesticides by GLC without preliminary separation, by comparison of the chromatogram with that obtained after dehydrochlorination in a heated magnesium oxide precolum. Electron capture detection was used. Much more precise results were achieved than is common in procedures with "on-column" reactions.

Derivative formation for HPLC is usually for different purposes from that for GLC, when alteration of the analyte is usually for better chromatographic performance, and secondarily to assist detector response. In HPLC, it is usually to aid detection. Shiga et al (Ref $7 \xi$ ) for example, attaches a fluorogenic structure to benomyl for a sensitivity of $0.008 \mathrm{mg} \mathrm{kg}$. FPLC derivatisation may be done before or after chromatography. Ross (Ref 77) reviews precolum reactions, and Frei et al (Ref 78 ) post-column derivatisations.

Colums. Thermally and chemically stable stationary phases, designed especially for GLC, such as the commercial "OV" series, are finding increasing use. The rate of appearance of "new" stationary phases appears to be declining. Even with the vast array avallable, a few standard colums are used predominately. Column optimisation consistent with stability is most essential in GCMS. In this author's laboratory, optimum separations are selected by use of a small range of low-bleed phases at low column loading. One such set 1s: methyl silicone (OV 101); methyl/phenyl silicone (OV 17); methyl/trifluoropropyl (OV 210), cyanopropyl/phenyl/methyl (OV 225) silicones, and Carbowax 20M, a high molecular-weight polyethylene giycol. These provide a variety of polarities and electron affinities, from which 
a suitable column may be derived. Vernon and Ogundipe (Ref 79) purified squalane for use as a standard stationary phase for retention studies; and also produced a catalytically hydrogenated Apiezon of high thermal stability for a similar purpose. Capillary colums, often considered too delicate for infection of the "dirty" extracts frequently produced in residue work, are belng reported more often, especially for difficult separations of residues. Buser (Ref 80) separates dioxins and dibenzofurans on a variety of capillary columns, and Krijgsman (Ref 81) analysed acetylated chlorophenols on capillaries. Support-coated open tubular (SCOT) colums are being more extensively used, although not especially in residue work. Schlieke and Pretorius (Ref 82) in a series of papers, gives an account of the characteristics of "whisker-wall" open tubular columns, which show promise for difficult residue separations.

Colums for HPLC showed signs, for a time, of proliferating in a similar manner to those for GLC In earlier years; this tendency has not continued, and most reports using HPLC refer to only a small variety of colums. They tend to be silica (for non-aqueous eluants) or permanently bonded phases such as C18 hydrocarbons (for "reverse-phase" systems where the mobile phase is aqueous or water-miscible). Some use is found for ion-exchange columns and "pairedIon" column, and there is a variety of size-separation columns, used, in residue work, ch1 chiefly in clean up separations rather than determinations. Except for gels, packings are generally of small particle size (5 to 10 microns) and packing efficiency is considered of great importance.

\section{HIGH PERFORMANCE LIQUID CHROMATOGRAPHY}

HPLC is increasing in usefulness in both cleanup and determination. Colum efficiencies and detectors are both constantly being improved.

The technique lends itself more profitably to alteration of the mobile phase than does GLC. Gradient elution, in particular, is used in a manner parallel with temperature programming In GLC, and mobile phase selection tends to take the place of stationary phase selection in the older technique.

Most papers refer to detection by ultraviolet absorption (UV), and a smaller number to fluorescent detection. UV detection with a mercury lamp at 1 ts strongest emission of $254 \mathrm{~nm}$ has the most adherants; some also use higher wavelengths avallable through phosphorus reemission. However, the variable wavelength detector is growing in use; firstly because a specific wavelength maximum for a compound may be chosen; and also because some newer pesticides, such as pyrethroids, may have their most useful absorption maxima at wavelengths lower than those avallable from a mercury lamp.

Refractive Index detection does not seem to have been reported in residues analysis. One wonders whether this property has been neglected; by careful selection of mobile phase and extraction details, it should be possible to use RI differences in many cases. When suitable, this could prove an attractive working tool.

\section{COMPUTER PROCESSING}

The use of the computer has greatly improved both identification and quantitation of residues, as well as providing data bank facilities. Wasserfallen (Ref 83) describes a programme which compares sample and standard chromatographic response at very closely defined "timewindows". No work has been found which applies this principle to residue analysis, but it should be eminently suitable.

Evaluation may also be achieved using a programme which fits Gaussian distributions to background-corrected chromatograms, helping to deal with unresolved peaks (Kampmann, Ref 84). Such techniques are not new, but the time-and-labour advantage of using computation is apparent. The paper cited refers to aminoacid resolution, but would appear applicable to residues.

McLeod and Lewis (Ref 85) have resolved a mixture of different pesticides by computation of response data from five GLC detectors running simultaneously. These were: electron capture, flame Ionisation, flame photometric (sulphur and phosphorus modes) and Coulson nitrogen detectors.

\section{AUTOMATED ANALYTICAL PROCEDURES.}

With the easier availability of microprocessors and various data-manipulating equipment, a number of automatic sampling devices for both GLC and HPLC are marketed. Laboratories with high sample throughput have found such systems to save time and cost in determinative steps. Application to preparative and cleanup steps is not yet far advanced, although some equipment for serial digestions is avallable; and liquid chromatographic cleanup should be readily adaptible to automatic processes. 
RE FERENCES

1. Y. Aoki, M. Takeda and M. Uchiyama, J. Ass, off. anal. Chem. 58, 1286-1293 (1975).

2. A.E. Smith, J. Chromat. 129, 309-314 (1976).

3. J. Mes and D.J. Campbell, Bull. Environ. Contam \& Toxicol. 16, 53-60 (1977).

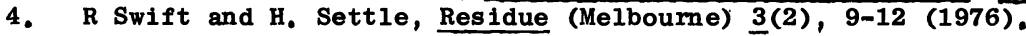

5. N.A. Smart, A.R.C. Hill and P.A. Roughan, Añalyst, 103, 770-772 (1978).

6. J.A. Coburn, I.A. Valdmanis and A.S.Y. Chau, J. Ass. Off, anal. Chem. 60, 224-228 (1977).

7. K. Berkane, G.E. Caissie and V.N. Mallet, J. Chromat. 139, 386-390 (1977).

8. S. Mierzwa and S. Witek, J. Chromat. 136, 105-111 (1977).

9. C. Wu and I.H. Suffet, Analyt. Chem. 4 49, 231-237 (1977).

10. H. Agemian and A,S,Y. Chau, J, Ass, off, anal. Chem. 60, 1070-1076 (1977).

11. K. Iukukara, 15. 'Eakeda and M. Uchiyama, Eise1 Shikensho Hokoku 94 14-18 (1976); C.A. 87, 182691c (1977).

12. H.R. McLean, S.Futugaki and J.T. Leffingwell, Bull, Environ, Contam \& Toxicol. 18, 247-250 (1977).

13. M.A. Luke, J.E. Froberg and H.T. Masumoto, J. Ass, off. anal. Chem. 58, 1020-1026 (1975).

14. K. Wagner and H. Frehse, Hofchenbr. Bayer PflSchutz-Nachr. 29, 54-66 (1976).

15. J. Hild and H.P. Thier, Dt, Lebensmitt, Rdsch, 73, 330-332 (1977).

16. W.E. Dale and J.W. Miles, J. Ass, off. anal. Chem. 59, 165-168 (1976).

17. H.0. Friestad, J.Ass, off, anal. Chem. 60 268-271 (1977).

18. J.F. Lawrence, D. Lewis and H.A. McLeod, J. agri. Fd. Chem. 25, 1359-1361 (1977).

19. M. Akerblom, Abstracts of Fourth International Congress of Pesticide Chemistry, Zurich, Switzerland (1978), Paper VI-702.

20. B. McMahon and J.A. Burke, J. Ass, off, anal. Chem, 61, 640-652 (1978).

21. G.M. Telling, D.J. Sissons and H.W. Brinkmann, J. Chromat, 137, 405-423 (1977).

22. H. Steinwandter and $H$. Schluter, $Z$. analyt, Chem, 286, 90-94 (1977).

23. R.H. de Vos, J. Chromat., to be published.

24. K.F. Ivie, Abstracts of Fourth International Congress of Pesticide Chemistry, Zurich, Switzerland (1978), Paper VI-710.

25. M.E. Getz, Talanta 22, 935-937 (1975).

26. J.N. Huckins, D.L. Stalling and J.L. Johnson, J. Ass, off, anal. Chem. 59, 975-981 (1976).

27. M. Osadchuk, E.Salahub and P. Robinson, J. Ass. off. anal. Chem. 60, 1324, 1327 (1977).

28. J. Solomon and W.L. Lockhart, J.Ass, off. anal. Chem. 60, 690-695, (1977).

29. H.L. Crist and R.F. Moseman, J. Ass, Off. anal. Chem。 $60,1277-1281$ (1977).

30. T. Stijve and E. Brand, Dt. Lebensmitt. Rdsch. 73, 41-43 (1977).

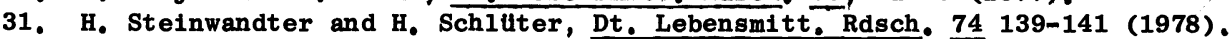

32. L.D. Johnson, R.H. Waltz, J.P. Ussary and F.E. Kaiser, J.Ass. off. anal. Chem. 59, 174-187 (1976).

33. S.G. Gorbach, S. Winkler and E. Gaudernack, Method XII-4, Deutsche Forschungsgemeinschaft, Rlickst andsanalytik von Pflanzenschutzmitteln, Verlag Chemie Weinheim/New York, 5th edition 1979, in press.

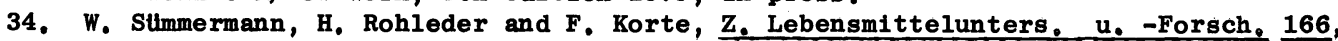
137-144 (1978).

35. S. Balint and L. Gyorf1, Abstracts of Fourth International Congress of Pesticide Chemistry, Zurich, Switzerland (1978), Paper VI-24.

36. J. Pflugmacher and W. Ebing, J. Chromat. 151, 171-197 (1978).

37. G. Wolff and W. Ebing, J. Chromat. 147, 213-219 (1978).

38. B, Zimmerli and B, Marek, Mitt. Geb. Lebensmittelunters, u Hyg, 66, 362-378 (1975).

39. K. A. Ramsteiner and W.D. HÖrmann, J. Chromat. 104, 438-442 (1975).

40. G.G. Still and E.R. Mansager, Chromatographia 8, 129-135 (1975).

41. W. Mittelstaedt, G.G. St111, H. Durbeck and F. Fuhr, J, Agr1C. Fd. Chem. 25, 908-912 (1977).

42. J. Kovac, V. Batora, A. Hankova and A. Szokolay, Bull. Environ. Contam, \& Toxicol. $13,692-697(1975)$.

43. L. Gay and M. Cerny, Mitt, Geb. Lebensmittelunters, u. Hyg. 66, 225-237 (1975).

44. M. Eichner, Chem, Labor Betrieb. 28, 299-302 (1977).

45. W. Ebing, J, Pflugmacher, M. Elchner, B. Karlhuber and $K_{0}$ Ramsteiner, Methods XII-2, S-12, S-13, S-14, Deutsche Forschungsgemeinschaft, Rlickstandsanalytik von Pflanzenschutzmitteln, Verlag Chemie Weinheim/New York, 5 th edition 1979, in press.

46. D.J. Caverly and R.C. Denney, Analyst 103, 368-374 (1978).

47. H. Oka, H. Matsumoto, N. Kawamura and T. Narafu, Shokuhin E1 selgaku Zasshi 17 283-289 (1976):; C.A. 86 3641w (1977).

48. G.D. Veith and L.M. Kiwus, Bull. Environ, Contam, \& Toxicol. 17, 631-636 (1977).

49. D.E. Ott and H.O. Friestad, J. Ass, Off, anal. Chem. 60, 218-223 (1977).

50. W. Specht, Lebensmittelchem.

51. D. Veierov and N. Aharonson, J. Ass, off, anal, Chem. 61, 253-260 (1978).

52. W.A. Aue, J. Chromatgr. Sci. 13, 329 (1978). 
53. W.P. Cochrane and R. Greenhalgh, Chromatographia 9, 255 (1976).

54. J,E. Lovelock, J. Chromat. 112, 29 (1975).

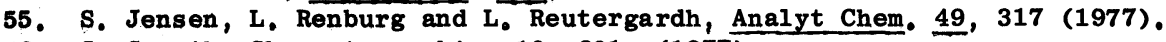

56. J. Sevcik, Chromatographia, 10, 601, (1977).

57. B. Brechbuhler, L. Gay and H, Jaeger, Chromatographia 10684 , (1977).

58. K. Buchmann, W. Emig, J. Rudolph and D. Tsotsos, Chromatographia 10, 684 (1977).

59. J. Desmarchelier, M. Bengston, M. Connell, W. Minett, B. Moore, M. Phillips, J. Snelson, R. Sticka and K. Tucker, Pestic。Sci. 8, 473 (1977).

60. R. Greenhalgh and $M_{0} A$. Nelson, J. Chromat. 128,157 (1976).

61. B. Kolb, M. Auer and P. Pospisal, J. Chromat. 134, 65 (1977).

62. N, Mellor, J. Chromat, 122, 396 (1976).

63. C.A. Burgett, D.A. Smith and H.B. Bente, J. Chromat. 134, 57 (1977).

64. R. Greenhalgh, J. Muller and W.A. Aue, J. Chromatgr Sc1. 16, (1978).

65. B.G. Luke and C.J. Dahl, J.Ass, off, anal, chem. 59,1081 (1976).

66. M.K. Baldwin, D. Bennett and K. I. Beynon, Pestic. Sci. 8,431 (1977).

67. H-J. St an, Chromatographia 10, 233 (1977).

68. B. L. Worobey and G.R.B. Webster, J. Ass. off, anal. Chem. 60, 213 (1977).

69. J.A. Coburn, B.D. Ripley and A.S.Y.Chau, J. Ass, off, anal. Chem. 59, 188, (1976).

70. B.D. Ripley and C.M. Simpson, Pestic. Sci. $8,487,(1977)$.

71. R. R. King, J, agric, Fd, Chem, 25,73 (1977).

72. S. Otto, W. Keller and N. Drescher, J. Envir. Sc1. Hlth, B12(3), 179 (1977).

73. M. Alam, Pestic. Sc1. 8, 167 (1977).

74. S.D. West and E.W. Day, J.Ass, off, anal. Chem. 60, 904 (1977).

75. B. Luckas, H. Pscheidl and D. Haberland, J. Chromat 147, 41 (198778).

76. N. Shiga, O. Matono and S. Goto, J. Pestic. Sci. (Jap) 2 , No 1 (from: Pesticide Abstracts, Vol 10 , No 8, 77-1806).

77. M, S.F. Ross, J. Chromatog. 141, 107 (1977).

78. R.W. Frei, L. Michel and W. Sant1, J. Chromat 142, 261 (1977).

79. F. Vernon and C.O.E. Ogundipe, J. Chromat. 132, 181 (1977).

80. H-R Buser, Anal Chem. 48, 1553 (1976).

81. W. Krijgsman and $C_{.} G$. Van der Kamp, J. Chromat 131, 412 (1977).

82. J.D. Schlieke and V. Pretorius, J. Chromat 131, 217, 223, 231 (1977).

83. K. Wasserfallen, F. Rinderknecht and E. Baumgartner, Chromatographia 10, 176 (1977).

84. L, Kampman, J. Chromat 150367 (1978).

85. H. A. McLeod and D. Lew 1 , J. Ass, off, anal, Chem 61,18 (1978). 